\title{
Biotechnology of Seed Crops: Genetic Engineering of Seed Storage Proteins
}

\author{
Alan L. Kriz \\ Department of Agronomy, University of Illinois, Urbana, IL 61801 \\ Brian A. Larkins \\ Department of Plant Sciences, University of Arizona, Tucson, AZ 85721
}

\begin{abstract}
During their development, seeds accumulate large amounts of storage, or reserve, products that are metabolized during germination and the early stages of seedling growth. Energy reserves include complex carbohydrates (starch) and lipids, while reserves of N, C, and $\mathrm{S}$ are accumulated in specific storage proteins. The uses of seed products by man are innumerable, ranging from fermentation of maize starch for alcohol production to refinement of soybean protein for use in infant formula. Agronomic crops, such as maize, wheat, oats, and soybeans, are grown because they generate large amounts of seed reserves per unit of cultivated land. A major concern of the agricultural industry is increasing yields of seed components to enhance the value of these crops. During the past century, plant breeders have been quite successful in developing new cultivars of seed crop plants that give higher yields of seed components than older ones. Advances have been made not only with respect to increasing the content of starch, oil, and protein in the seed, but also, in some cases, in altering the quality of these components. For example, naturally occurring genetic variation has been exploited in the development of maize cultivars with modified starch content (Nelson, 1979; Shannon and Garwood, 1984) and increased or altered oil content (Alexander 1988, 1989; Weber, 1987). In a similar manner, the composition of soybean oil has been altered through selection to decrease the content of linolenic acid, resulting in a product with a more desirable flavor (Fehr, 1989; Hymowitz, 1987).
\end{abstract}

The synthesis of carbohydrates and lipids involve complex metabolic processes, and although a great deal is known about these pathways, it remains to be determined how recent advances in genetic engineering technology will aid in the modification of these processes to enhance seed quality. For example, alteration of the activities of one or two enzymes in the starch biosynthetic pathway might allow for the accumulation of desirable intermediates of starch biosynthesis. Such a situation may, however, result in a serious imbalance in the overall carbon flow in the seed, which could affect factors such as grain yield and seed viability. Conventional selection and breeding strategies may, therefore, be more efficient than the use of genetic engineering in the development of crop cultivars possessing seed carbohydrates and lipids of desirable composition (Alexander, 1988).

An important aspect of seed quality that is directly amenable to manipulation through genetic engineering involves the nutritional characteristics of seed proteins. In most cases, seed proteins of any one crop do not contain sufficient quantities of certain amino acids that are essential in the diet of humans and other monogastric animals (Nelson, 1969). Generally, cereals are most limiting in lysine and tryptophan, and legumes are deficient in the sulfur amino acids methionine and cysteine (Table 1). The economic advantages for increasing the nutritional quality of seed proteins are enormous: estimates of total protein production for each of two major seed crops in the United States, maize and soybeans, exceed 16 million tons annually (Wilson, 1987). Development of nutritionally balanced seed proteins in high-production crops like maize and soybean would benefit all areas of the agricultural industry concerned with grain production for human and livestock consumption.

Plant breeders have had only limited success in improving the nutritional quality of seed proteins, primarily because genes encod-

Figures 2 and 3 were previously published in Science. ing seed storage proteins with high levels of essential amino acids do not normally exist in any given species. Modification of genes encoding seed proteins by using genetic engineering techniques may, therefore, be an ideal solution to this problem. However straightforward the genetic engineering approach might be, certain problems must be overcome for successful application of this technology to the particular problem of improving seed protein quality. It is a relatively simple matter to isolate recombinant DNA clones corresponding to genes that encode specific proteins and to modify these clones by in vitro mutagenesis so that they contain codons for desired amino acids (Kramer et al., 1984; Wallace et al., 1988a). In addition, recent progress in gene transfer technology will soon allow for the routine production of transgenic maize and soybean plants (Hinchee et al., 1988; Klein et al., 1988; Rhodes et al., 1988). It must be recognized, however, that seed storage proteins assume specific conformational structures within the seed and that any modifications to these proteins must allow for their proper deposition in the cell. As discussed below, most of the work in this area has been conducted with respect to the extent to which storage proteins of maize and soybean seeds can be modified without perturbing their structural organization.

\section{CHARACTERISTICS AND CLASSIFICATION OF SEED STORAGE PROTEINS}

The major proteins of most seeds are referred to as storage proteins. These proteins accumulate to high levels during seed devel-

Table 1. Amino acid composition of total maize and soybean seed protein and purified storage protein fractions.

\begin{tabular}{|c|c|c|c|c|}
\hline \multirow[b]{2}{*}{$\begin{array}{l}\text { Amino } \\
\text { acid }\end{array}$} & \multicolumn{2}{|c|}{ Maize } & \multicolumn{2}{|c|}{ Soybean } \\
\hline & $\begin{array}{c}\text { Total } \\
\text { protein }^{\mathrm{y}}\end{array}$ & $\begin{array}{c}\text { Alpha } \\
\text { zein }^{x}\end{array}$ & $\begin{array}{c}\text { Total } \\
\text { protein }^{w}\end{array}$ & Glycinin $^{\mathrm{v}}$ \\
\hline Glycine & 6.7 & 2.2 & 7.4 & 7.8 \\
\hline Alanine & 11.1 & 13.3 & 6.0 & 6.7 \\
\hline Valine & 5.6 & 3.6 & 5.5 & 5.6 \\
\hline Leucine & 12.1 & 18.7 & 8.0 & 7.2 \\
\hline Isoleucine & 3.6 & 3.8 & 4.7 & 4.6 \\
\hline Serine & 5.8 & 6.3 & 6.3 & 6.6 \\
\hline Threonine & 4.0 & 3.0 & 4.3 & 4.2 \\
\hline Tyrosine & 3.0 & 3.5 & 2.6 & 2.5 \\
\hline Phenylalanine & 3.8 & 5.2 & 3.7 & 3.9 \\
\hline Tryptophane & 0.3 & nd & 0.7 & nd \\
\hline Proline & 9.3 & 10.7 & 6.5 & 6.3 \\
\hline Methionine & 1.4 & 0.9 & 1.2 & 1.0 \\
\hline Cysteine & 2.1 & 1.0 & 1.6 & 1.1 \\
\hline Lysine & 2.4 & 0.1 & 5.5 & 4.1 \\
\hline Histidine & 2.1 & 1.0 & 2.1 & 1.8 \\
\hline Arginine & 3.3 & 1.2 & 5.9 & 5.9 \\
\hline $\mathrm{Asx}^{4}$ & 7.0 & 5.1 & 11.3 & 11.8 \\
\hline$G l x^{\ddagger}$ & 16.4 & 21.4 & 16.5 & 18.8 \\
\hline
\end{tabular}

${ }^{2}$ Expressed as mole percent; nd, not determined.

yAverage of values in Nelson (1969) and Mosse and Baudet (1983).

×From Wilson (1987).

wAverage of values in Smith and Circle (1972) and Mosse and Baudet (1983).

"From Kitamura and Shibasaki (1975).

"Determined as aspartic acid + asparagine.

'Determined as glutamic acid + glutamine. 
opment, usually in membrane-bound aggregates called protein bodies, and are degraded during germination to provide a source of $\mathrm{N}, \mathrm{C}$, and $\mathrm{S}$ for the early stages of seedling growth (reviewed by Higgins, 1984; Shotwell and Larkins, 1989). Seed storage proteins are generally distinguished on the basis of solubility as water-soluble albumins, saline-soluble, water-insoluble globulins, alcohol-soluble prolamins, and dilute acid- or alkali-soluble glutelins (Osborne, 1924). There is a general distinction among plant types with respect to the type of storage proteins found in the seed. Dicotyledenous plants, such as legumes, contain globulin types, while monocots, such as cereals, usually contain predominantly the prolamin types. Globulins and prolamins are quite different in their structures and in the mechanisms by which they are synthesized and deposited in the seed, and the two types are considered separately in the following sections.

\section{MODIFICATION OF MAIZE ZEINS}

Zeins, the prolamins of maize grain, account for $40 \%$ of the protein in maize kernels. These proteins can be fractionated into three distinct groups based on differential solubility in aqueous alcohol solutions (Esen, 1986). Recombinant DNA clones that correspond to genes encoding each of the different zein types have been characterized at the nucleotide sequence level (Kirihara et al., 1988; Marks and Larkins, 1982; Pedersen et al., 1986; Prat et al., 1985), and comparative sequence analysis allows for the separation of these genes into four groups designated alpha, beta, gamma, and delta. The alpha zeins, $M r 22,000$ and 19,000, are the most abundant group and account for $70 \%$ of the total zein fraction in mature grain. Extensive charge heterogeneity in alpha zeins is observed by isoelectric-focusing gel electrophoresis (Righetti et al., 1977; Wilson, 1984), and molecular analyses have demonstrated that these proteins are encoded by a large, multigene family (Hagen and Rubenstein, 1981; Wilson and Larkins, 1984). In contrast, the beta $(\mathrm{Mr}$ 14,000), gamma ( $M r 27,000$ and 16,000), and delta $(M r 10,000)$ zeins are each encoded by only one or two genes (Kirihara et al., 1988; Prat et al., 198.5; Wilson and Larkins, 1984). None of the zein genes analyzed to date have been found to encode even a single lysine residue, and in only one case has a tryptophan codon been identified (reviewed by Rubenstein and Geraghty, 1986).

All four of the zein types are synthesized as preproteins in the endosperm between 10 and 40 days after pollination (Hurkman et al., 1981; Rubenstein and Geraghty, 1986; Soave and Salamini, 1984). Zein mRNAs are translated on rough endoplasmic reticulum (RER) and, following cleavage of the signal peptide, zein proteins accumulate within the lumen of the RER as dense, membrane-bound protein bodies (Larkins and Hurkman, 1978). As viewed through the electron microscope, protein bodies are roughly spherical structures $\approx 1 \mu \mathrm{m}$ in diameter (Fig. 1A). Immunocytochemical analyses have revealed that maize endosperm protein bodies are complex structures with unequal distribution of zeins (Lending et al., 1988). Immunolocalization of alpha zeins within protein bodies is shown in Fig. 1B. Note that these proteins are generally distributed within the protein body matrix. In contrast, the beta (Fig. 1C, panels 14) and gamma (Fig. 1D, panels 1-3) zeins generally occur on the surface of the protein bodies, or in dark-staining inclusions.

The poor nutritional quality of maize grain protein is primarily due to the near absence of lysine and tryptophan, both essential for humans and other monogastric animals, in the zein fraction (Table 1). In maize mutants such as opaque-2, opaque-7, and floury-2, the zein content of the endosperm is decreased and the relative lysine content is increased, resulting in grain of a more desirable nutritional quality (Nelson, 1969). These mutants primarily reduce synthesis of the alpha zeins (Soave and Salamini, 1984), which affect both the size and morphology of protein bodies (Christianson et al., 1974). The endosperm of these mutants has a soft, floury texture. The mutant grains are lower yielding than normal grains, and the soft kernel phenotype results in decreased kernel density, increased susceptibility to insect damage, and an increased frequency of kernel breakage (Mertz, 1986; Ortega and Bates, 1983). These agronomically undesirable features have limited the use of high-lysine maize mutants as a food source.
Since the technology required for gene transfer into maize will probably be available in the near future (Klein et al., 1988; Rhodes et al., 1988), in vitro genetic engineering of genes encoding zeins may provide an alternative to traditional breeding methods in the development of nutritionally desirable maize grain. This approach involves the use of recombinant DNA technology to modify zein genes so that lysine and tryptophan residues are incorporated into zein polypeptides. Genes encoding alpha zeins, the most abundant zein type, are logical candidates for modification through genetic engineering techniques. These genes have been extensively characterized with respect to nucleotide sequence, revealing the presence of a 20-amino-acid repeat within the corresponding polypeptides (Marks and Larkins, 1982; Spena et al., 1982). It has been proposed that these repeated sequences exist as antiparallel alpha helices separated by glutamine-rich turn regions (Argos et al., 1982). This structural model accounts for the tight packing of alpha zeins within protein bodies by way of hydrophobic and weak polar interactions between polypeptides. Such interactions must be taken into account when designing strategies for modification of alpha zeins: incorporation of highly charged lysine residues into these polypeptides may interfere with these associations and disrupt protein body formation. Clearly, any modifications must be such that they have no adverse effect on protein body structure and organization within the endosperm.

Even if the gene transfer technology for maize were presently available, a rapid, reliable, and sensitive assay for protein body formation would be necessary for the evaluation of modified gene constructions. Such an assay is provided by translation of zein mRNAs

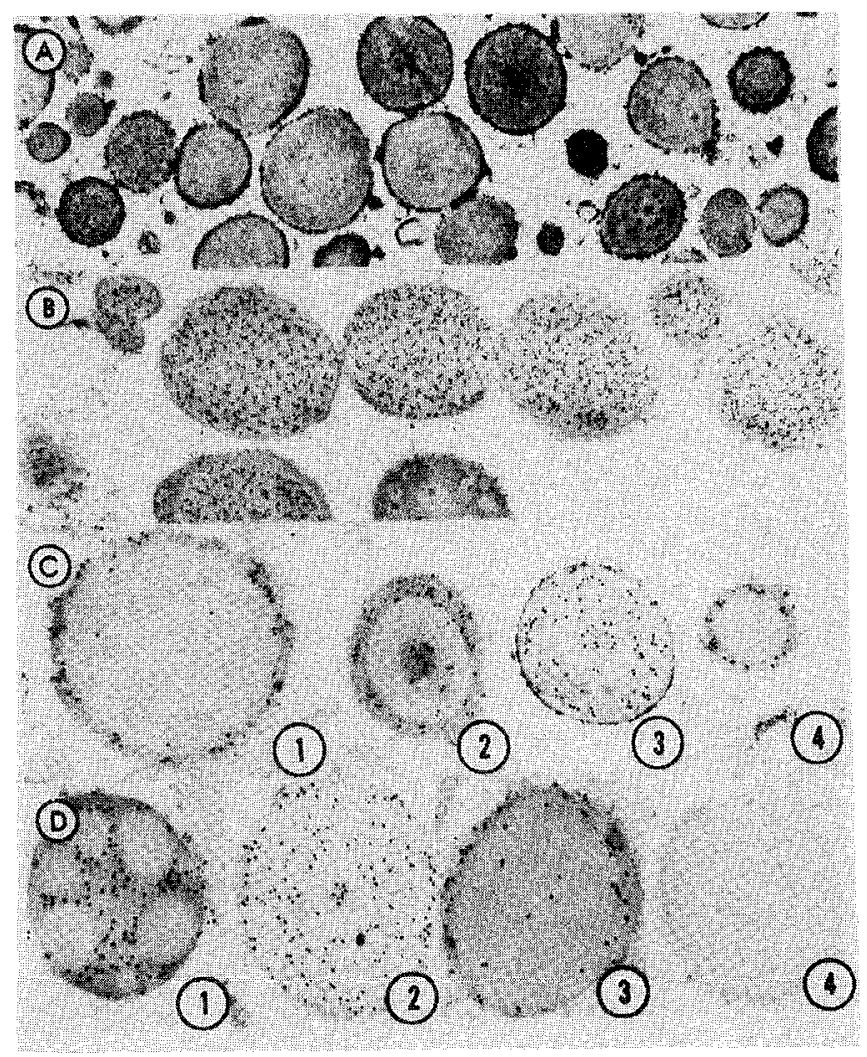

Fig. 1. Analysis of purified maize protein bodies by transmission electron microscopy (TEM). Protein bodies were isolated from maize endosperm at 18 days after pollination by sucrose density gradient ultracentrifugation and processed for TEM analysis as described in Lending et al. (1988). (A) Protein bodies stained with lead citrate and uranyl acetate. $\times 9230$. (B) Protein bodies reacted with antibodies specific for alpha zeins followed by immunogold staining. The gold particles appear as discrete dots and serve to localize alpha zeins within the protein body matrix. $\times 28,400$. (C) Selected protein bodies showing immunogold localization of beta zeins. $\times 39,050$. (D) Staining patterns obtained with antibodies to gamma zein (panels 1-3) and with preimmune serum as a negative control. $\times 39,050$. Reproduced with permission from Larkins et al. (1989). 
in Xenopus oocytes. Injection of endosperm mRNA into Xenopus oocytes results in the synthesis and aggregation of zein polypeptides in membrane-bound structures with physical characteristics similar to those of protein bodies from maize endosperm (Hurkman et al., 1981). In addition, in vitro transcription systems (Melton et al., 1984) allow for efficient production of mRNA corresponding to any given cDNA clone. By combining these two technologies, Wallace et al. (1988b) demonstrated that a single alpha zein is capable of forming protein bodies in Xenopus oocytes. Thus, it is now possible to evaluate the effects of lysine substitutions and other modifications in zein polypeptides on protein body formation within RER.

The amino acid sequence of an $M r$ 19,000 alpha zein, as deduced from the nucleotide sequence of a cDNA clone, is shown in Fig. 2. The sequence is arranged to show the alpha-helical amino acid repeats in a manner corresponding to the structural domains proposed by Argos et al. (1982). According to this model, the 35 amino-terminal residues and the eight carboxyl-terminal residues remain unpaired and do not have a major role in determining the structure of zein polypeptides. Three types of changes, listed to each side of the amino acid sequence, were introduced into the polypeptide by modifying the corresponding cDNA clone. These changes consisted of single and double substitutions of lysines in place of neutral amino acids (constructions 1 to 5), insertion of short oligopeptides rich in lysine and tryptophan (constructions a to c), or the insertion of a 149 amino acid hydrophilic peptide derived from the coat protein of the animal virus SV40 (indicated by an asterisk). The lysine substitution mutants were generated by sitedirected, oligonucleotide-mediated mutagenesis (Kramer et al., 1984) of the original cDNA clone. This technique involves changing a single nucleotide to alter a codon at a targeted position in the cloned DNA sequence. The small peptide insertions were introduced by cloning corresponding synthetic, double-stranded oligonucleotides into the indicated positions of the original cDNA sequence; the large peptide was introduced by inserting a DNA fragment from the SV40 genome.

To determine whether the altered zeins were capable of aggregating into protein bodies, artificial mRNAs were synthesized from the modified cloned sequences in an SP6 polymerase in vitro transcription system. Each of these mRNAs, in addition to native zein mRNA, was injected into Xenopus oocytes, and after an 18-h incubation period, ${ }^{3} \mathrm{H}$-labeled leucine was injected to radiolabel the modified proteins. Oocyte homogenates were then subjected to density ultracentrifugation in metrizamide gradients to separate the membrane components (Fig. 3, top). Fractions were collected from

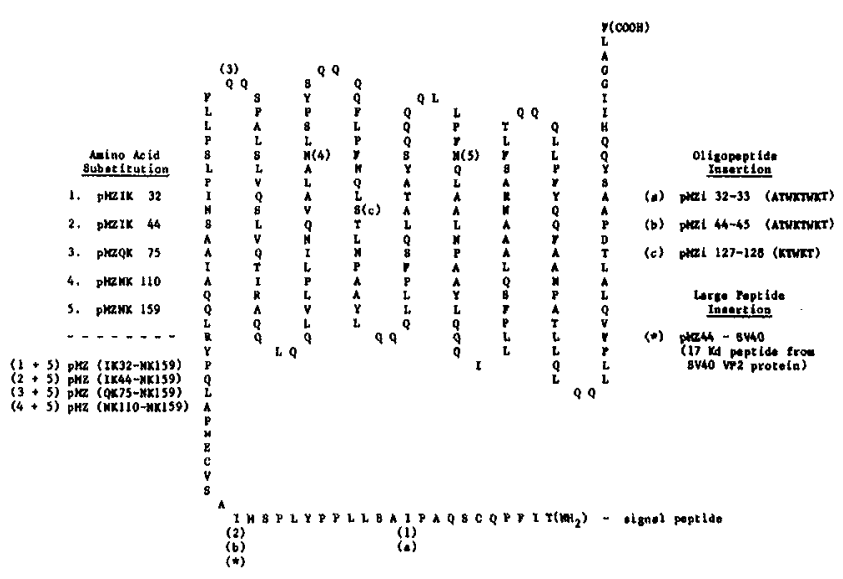

Fig. 2. Primary amino acid sequence of an $M r$ 19,000 alpha zein as deduced from the cDNA clone cZ19c1 (Marks et al., 1985). The signal peptide of 21 amino acids is not shown. The names of the modified clone constructions are shown on the sides of the sequence, and these correspond to the change introduced in that particular construct; for example, construct 1 involves a change from an isoleucine residue to a lysine at position 32. Modifications included single amino acid substitutions (constructs 1-5), oligopeptide insertions (a-c), or the insertion of a $17 \mathrm{kDa}$ polypeptide from an SV40 protein $(*)$. Reproduced with permission from Wallace et al. (1988a). the gradients, and zeins were extracted from each fraction by the addition of ethanol to a final concentration of $70 \%$. Following electrophoresis in SDS-polyacrylamide gels, ${ }^{3} \mathrm{H}$-labeled zeins were visualized by fluorography. Protein bodies from oocytes injected with total zein mRNA form a band deep in the gradient (Fig. 3A) at a density corresponding to that of protein bodies isolated from endosperm (Hurkman et al., 1981). The unmodified $M r$ 19,000 alpha zein alone also forms protein bodies (Fig. 3B), which is consistent with the structural model of zein aggregation proposed by Argos et al. (1982). Radiolabeled alpha zein exogenously added to oocyte homeogenates remains at the top of the gradient (Fig. 5C), indicating that passive association with dense membranous particles is not responsible for the sedimentation behavior of the proteins synthesized in the oocytes.

Protein bodies containing alpha zein alone are slightly less dense than those containing the full zein complement, suggesting that the

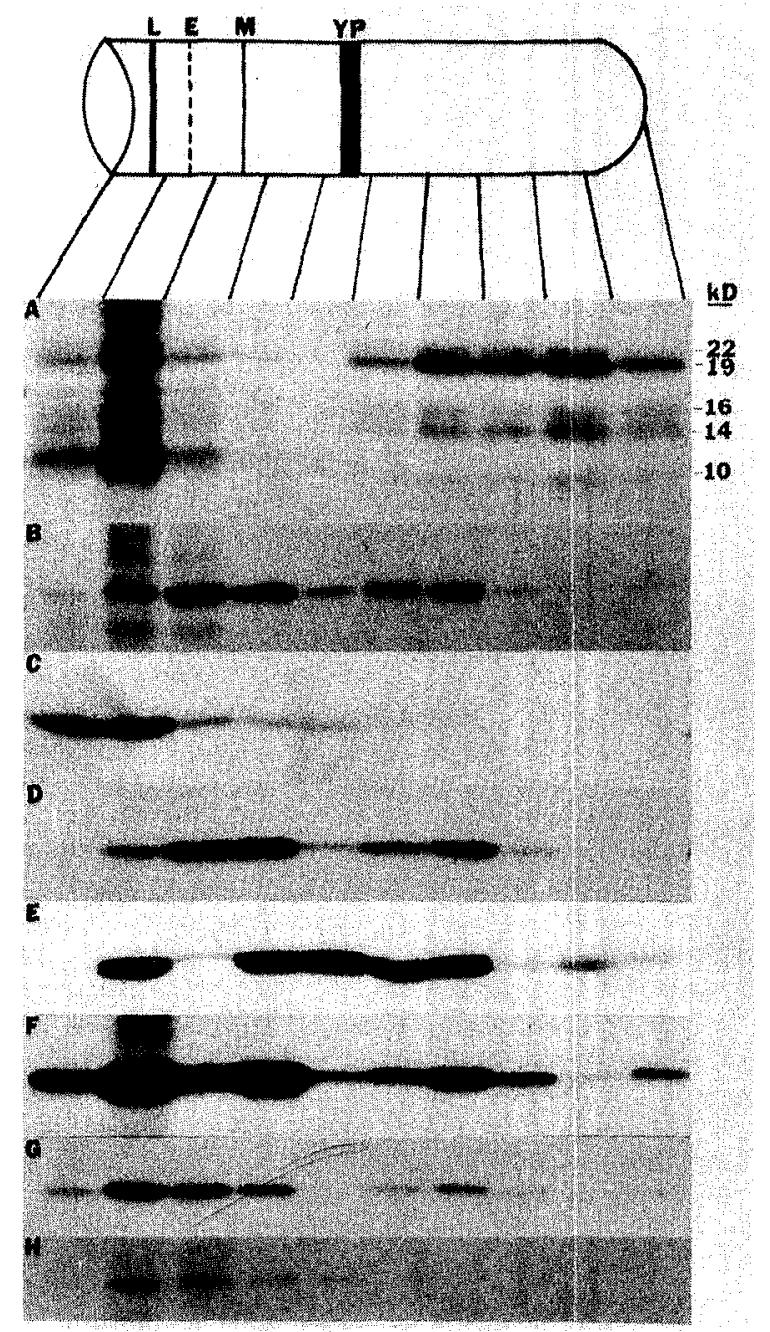

Fig. 3. Density gradient separation of zein-containing protein bodies from Xenopus oocytes injected with mRNA. Oocytes were injected with either native zein mRNA (panel $\mathbf{A}$ ) or synthetic mRNA transcripts (panels BH) and ${ }^{3} \mathrm{H}$-labeled leucine as described in Wallace et al. (1988a). Oocyte homogenates were subjected to centrifugation in 4-ml gradients of $10 \%$ to $50 \%$ metrizamide to separate subcellular components as shown in the top drawing ( $L$, lipids; $\mathrm{E}$, endomembranes; $\mathrm{M}$, mitochondria; YP, yolk platelets). Gradients were fractionated manually, and the distribution of radioactively labeled alcohol-soluble proteins throughout the gradients were determined by SDS-PAGE and fluorography. Panels B through H correspond to the synthetic mRNAs indicated in Fig. 2: (B) unmodified Mr 19,000 alpha zein; (C) exogenous ${ }^{3} \mathrm{H}-$ labeled zein added to oocyte homogenate; (D) pMZIK 32; (E) pMZ (NK110-NK159); (F) pMZi 3233; (G) pMZi 32-33; (H) pMZ44-SV40. The molecular weight of zeins is shown in panel A; modified zeins migrated at $M r 19,000$, except the MZA4-SV40 protein, which had an Mr of 35,000 due to the large poly- 
other zein types influence protein body density. Protein bodies containing the single alpha zein are smaller than those containing all of the zein types, and their lower density may be due to a higher lipid : protein ratio in the smallerstructures (Wallace et al., 1988b). Zeins modified by lysine substitution (Fig. $3 \mathrm{D}$ and E) or oligopeptide insertion (Fig. $3 \mathrm{~F}$ and $\mathrm{G}$ ) exhibit sedimentation patterns similar to that of the unmodified zein. Only the large peptide insertion (Fig. $3 \mathrm{H}$ ) interfered with the aggregation of the polypeptide into protein bodies. Thus, introduction of lysine residues into an alpha zein polypeptide, either through substitution or insertion, does not appear to impair aggregation of zeins within protein bodies.

Although the environment within Xenopus oocytes is quite different from that of maize endosperm cells, the oocyte compartmentalization assay provides valuable information about the process of zein deposition in maize. The ability of individual alpha zeins to associate into protein bodies in oocytes demonstrates that such aggregation is largely a function of interactions between the polypeptides after they are translocated into the lumen of the RER. The addition of lysine residues to an alpha zein, either by amino acid substitution or insertion, does not interfere with the formation of protein bodies. It is therefore likely that lysine-containing zeins would be packaged into protein bodies in maize endosperm; this could be tested once the appropriate gene transfer technology is available for maize.

\section{POTENTIAL FOR MODIFICATION OF SOYBEAN GLYCININ}

Seed globulins are generally classified on the basis of their sedimentation properties. In most dicots, these proteins fall into two classes with sedimentation coefficients of 11-12S and 7-8S (Derbyshire et al., 1976). In soybean, the $12 \mathrm{~S}$ globulin predominates and usually constitutes $\approx 62 \%$ of the total globulin fraction. This $12 \mathrm{~S}$ globulin, termed glycinin, accounts for $\approx 42 \%$ of the total seed protein. Glycinin exists in seeds as a hexameric complex of $\mathrm{Mr}$ 360,000 and is composed of six subunits, each of which consists of an $M r 40,000$ acidic polypeptide linked by a disulfide bond to an $M r$ 20,000 basic polypeptide (Nielsen, 1985a). A limited amount of heterogeneity has been observed for glycinin polypeptides (Nielsen, 1984), but all of these proteins are characterized by their low ( $2 \%$ or less) content of sulfur amino acids (Nielsen, 1985b). Five different subunits have been identified which fall into two classes: Group I consists of three members, each of which contains five to eight methionine residues; Group II consists of two members, each containing three methionine residues (Nielsen, 1985a). DNA clones corresponding to genes encoding each of the glycinin subunits have been characterized at the nucleotide sequence level (Nielsen et al., 1989).

Soybean storage proteins are localized in protein bodies, but the mechanism for their deposition is quite different than that of zeins in maize endosperm. The synthesis, processing, and transport of $12 \mathrm{~S}$ globulins have recently been reviewed in detail (Chrispeels, 1985; Shotwell and Larkins, 1989), and only a brief overview is presented here. Glycinin subunits are synthesized throughout most of cotyledon development on RER as precursor polypeptides termed proglycinins (Barton et al., 1982; Turner et al., 1982). These precursors contain amino-terminal leader sequences that are cotranslationally removed during translocation into the lumen of the RER. In the RER, an intramolecular disulfide bond forms in proglycinin, after which these polypeptides assemble into 9S trimers (Barton et al., 1982). These trimers are transported via the golgi apparatus to the vacuole, where they associate to form protein bodies. Before protein body formation, each proglycinin molecule of the trimer is cleaved into the $M r$ 40,000 acidic and $M r$ 20,000 basic polypeptides, which remain associated via the disulfide bond (Nielsen, 1984; Staswick et al., 1984). Two trimers then associate to form the hexameric $12 \mathrm{~S}$ holoprotein.

Since sulfur amino acids are limiting in soybean seed proteins (Table 1), modification of glycinin polypeptides by addition of methionine residues would enhance the nutritional quality of soybean meal. As discussed above for maize zein polypeptides, any modifications to storage proteins must allow for proper deposition within the seed. The structural domains of $12 \mathrm{~S}$ globulins and the mechanisms by which these proteins are transported and processed within the seed are similar in all plants that have been examined (Shotwell and Larkins, 1989). Strong structural constraints may, therefore, exist in these proteins, and any modification of glycinin subunits by genetic engineering must allow for proper assembly of glycinin monomers into the hexameric $12 \mathrm{~S}$ protein.

Recognizing the need for a rapid and sensitive assay for glycinin assembly, Nielsen and coworkers at Purdue Univ., West Lafayette, Ind., investigated self-assembly of proglycinin in vitro (Dickinson et al., 1987). This assay involved the in vitro transcription of cDNA clones corresponding to individual glycinin genes to produce synthetic mRNAs, which were then translated in a cell-free rabbit reticulocyte lysate system. Synthesis of proglycinin in the translation reactions was monitored by the incorporation of ${ }^{3} \mathrm{H}$-labeled leucine into the polypeptide. Following termination of the translation reaction, the samples were incubated for various times to allow for self-assembly of the monomers into higher-order structures. Assembly was evaluated by subjecting the reaction mixtures to sucrose density gradient ultracentrifugation. After a 1-h incubation, all of the radiolabeled proglycinin polypeptides existed as $3 \mathrm{~S}$ monomers, but after $30 \mathrm{~h}$, all of the monomers were assembled into 9S trimers. Using this assay, Dickinson et al. (1987) demonstrated that removal of the signal peptide from proglycinin is required for proper assembly and that deletion of an internal hydrophobic domain of 27 amino acids in the basic subunit, which is conserved among all $12 \mathrm{~S}$ seed globulins, prevented self-assembly. Since the presence of the hydrophobic signal sequence or absence of the conserved domain of the basic subunit would alter the structure of proglycinin monomers, these results indicate that assembly into 9S trimers depends on the proper conformation of the monomers.

Although the above experiments demonstrated that proglycinin monomers could self-assemble in vitro to form trimers, no evidence was obtained for hexamer formation. To investigate assembly of proglycinin into $12 \mathrm{~S}$ hexamers, Dickinson et al. (1989) developed an assay to evaluate reassembly of proglycinin trimers and mature glycinin subunits (Fig. 4). In this system, native, mature glycinin was dissociated in a low-ionic-strenght buffer to yield $3 \mathrm{~S}$ monomers and $9 \mathrm{~S}$ trimers. These mature subunits were mixed with either proglycinin monomers or trimers produced by the self-assembly process under conditions of high ionic strengths that promote reassembly of trimers into hexamers. The reassembly process was evaluated by subjecting the assay reaction to sucrose density ultracentrifugation and determining the amount of radiolabeled proglycinin in the 9S and $12 \mathrm{~S}$ fractions.

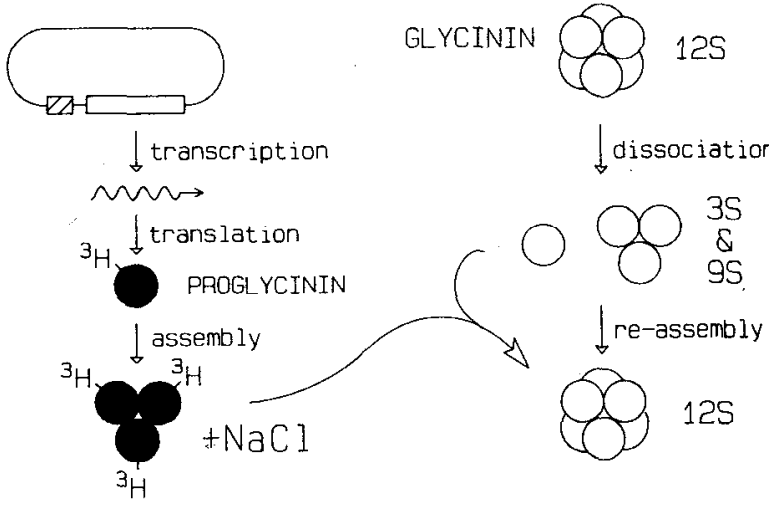

Fig. 4. Schematic diagram of in vitro assays for glycinin assembly. The procedure for self-assembly of proglycinin monomers synthesized in vitro is shown on the left side of the diagram. Solid circles represent ${ }^{3} \mathrm{H}$-labeled proglycinin synthesized at the direction of a glycinin cDNA clone. Open circles represent mature, native glycinin subunits, isolated from seeds, which had undergone post-translational cleavage in vivo to yield disulfidelinked acidic and basic polypeptides. The reassembly assay involves incubation of either proglycinin monomers or trimers with dissociated mature glycinin under conditions favoring hexamer formation. Reproduced with permission from Dickinson et al. (1989). 


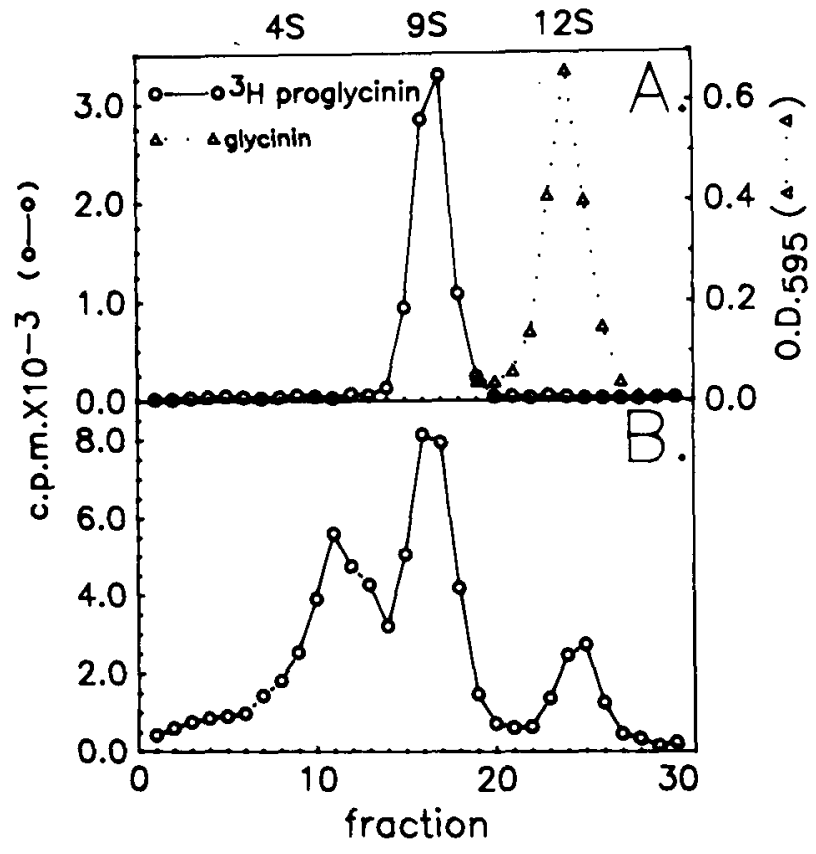

Fig. 5. Sucrose density gradient profiles of complexes formed by proglycinin trimers and monomers in the reassembly assay. (A) Self-assembled radiolabeled proglycinin trimers were isolated from a sucrose gradient and incubated with dissociated native glycinin subunits. Radiolabeled polypeptides are present only in the $9 \mathrm{~S}$ fraction, indicating that these polypeptides did not assemble into hexamers. The presence of unlabeled protein in the $12 \mathrm{~S}$ fraction (dashed line) demonstrates that the mature glycinin subunits had reassembled into hexamers. (B) Same as (A) except that radiolabeled proglycinin monomers were used. The presence of a small amount of radioactively labeled polypeptides in the $12 \mathrm{~S}$ fraction indicates that some of these monomers assembled into hexamers. Reproduced with permission from Dickinson et al. (1989).

The results of a reassembly experiment are shown in Fig. 5 . When 9S proglycinin trimers were tested in this assay, the mature, unlabeled subunits reassembled into the $12 \mathrm{~S}$ hexamer form, but none of the radiolabeled proglycinin trimers were found in the $12 \mathrm{~S}$ fraction (Fig. 5A). Instead, these molecules remained as 9S trimers. Proglycinin monomers, however, were able to associate with mature glycinin subunits to form $12 \mathrm{~S}$ hexamers (Fig. 5B). Note that only a small portion of proglycinin monomers, as measured by the amount of radiolabeled protein, assembled into the hexameric form. The bulk of the radioactivity was found in the $9 \mathrm{~S}$ fraction, indicating that most of the proglycinin monomers assembled into trimers. Taken together, the results of these two experiments indicate that, although some proglycinin monomers are capable of associating with mature subunits to form a hexamer, assembly of proglycinin appears to be blocked at the trimer stage. This barrier to assembly could be structural in nature, and it is likely that cleavage of proglycinin into its acidic and basic polypeptide components, which normally occurs in protein bodies, results in a conformational change that allows for hexamer formation.

To determine whether proteolytic cleavage of proglycinin trimers would relax any conformational constraints limiting assembly into hexamers, proglycinin synthesized in vitro was permitted to form trimers and then treated with the nonspecific protease papain. Mild papain treatment resulted in a slight shift in the sedimentation profile of the trimers, but they clearly persisted as trimers (Fig. 6A). This sedimentation profile also shows that, unlike trimers, monomers are quite sensitive to papain treatment and are rapidly degraded by the protease. Analysis of papain-treated trimers by SDS-PAGE (Fig. $6 \mathrm{~B}$ ) indicated that cleavage occurred at multiple sites in the proglycinin subunits, presumably in regions exposed on the surface of the trimer complex. The sedimentation profile indicates, however, that the basic trimer structure is preserved after proteolysis. As expected, untreated trimers do not assemble into hexamers (Fig. 6C). Use of papain-treated trimers in the reassembly assay resulted in a prom-
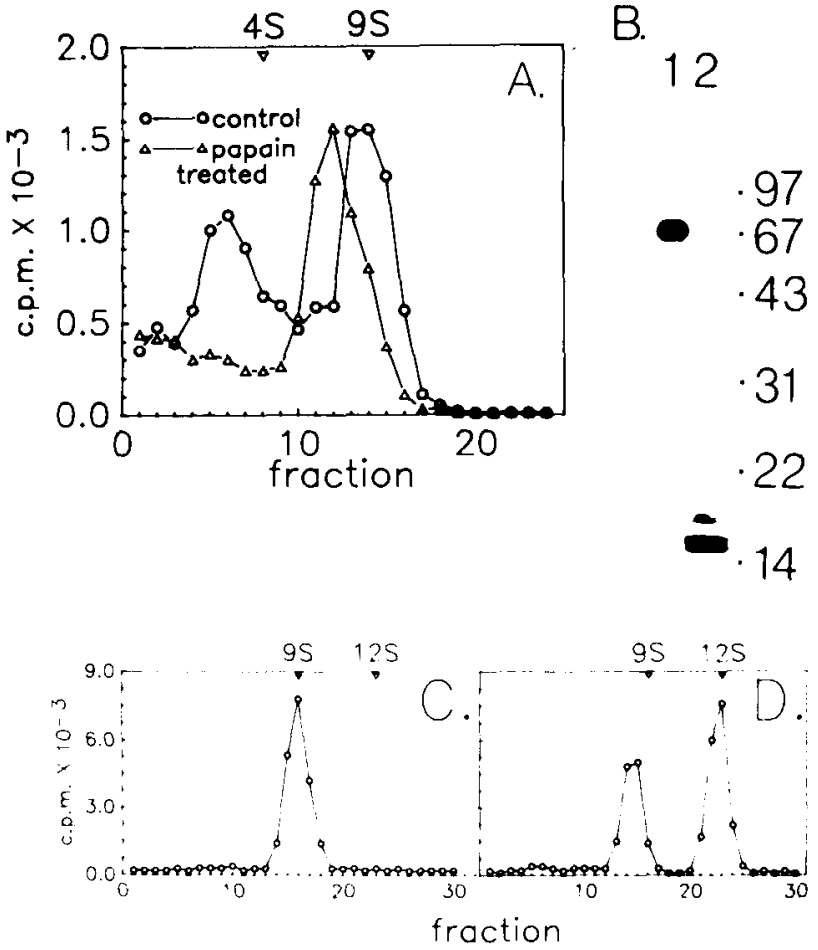

Fig. 6. Effect of partial proteolysis on reassembly of proglycinin trimers. (A) Proglycinin was synthesized in vitro. allowed to partially self-assemble, then treated with the nonspecific protease papain. The sample was then fractionated by density gradient ultracentrifugation (triangles). Analysis of an untreated aliquot from the assembly reaction (circles) is shown for comparison. (B) Trimer fractions from (A) were subjected to SDS-PAGE and fluorography to assess the extent of proteolysis. Lane 1, untreated trimers; lane 2, papain-treated trimers. Analysis of sedimentation profiles of complexes formed by untreated trimers $(\mathbf{C})$ and papain-treated trimers (D) indicates that partial proteolysis allows for formation of $12 \mathrm{~S}$ hexamers. Reproduced with permission from Dickinson et al. (1989).

inent $12 \mathrm{~S}$ peak (Fig. 6D), indicating that proglycinin trimers are capable of forming hexamers subsequent to proteolysis treatment. Although papain treatment does not result in specific cleavage of proglycinin into acidic and basic polypeptides, as is the case in protein bodies, the nonspecific cleavage is apparently sufficient to relax any conformational constraints that interfere with in vitro assembly into $12 \mathrm{~S}$ hexamers.

The assembly of glycinin subunits into the $12 \mathrm{~S}$ hexameric protein clearly involves proper post-translational processing of the proglycinin precursors. The in vitro reassembly assay provides a rapid and sensitive means of determining the extent to which glycinin subunits can be modified through genetic engineering techniques to enhance the nutritional quality of soybean seed protein by the addition of methionine residues. Apparently, the ability of modified subunits to assemble in vitro is reflected in seeds of transformed plants (N.C. Nielsen, personal communication). Thus, it is now possible to evaluate methionine-enriched glycinin polypeptides for their ability to assemble into the mature holoprotein within seeds. Subsequent transfer of modified glycinin gene constructions into soybean plants will result in production of seeds with protein of desirable nutritional quality.

\section{Literature Cited}

Alexander, D.E. 1988. Breeding special nutritional and industrial types, p. 869-880. In: G.F. Sprague and J.W. Dudley (eds.). Corn and com improvement. 3rd ed. Amer. Soc. Agron., Madison, Wis.

Alexander, D.E. 1989. Maize, p. 431-437. In: G. Robbelen, R.K. Downey, and A. Ashri (eds.). Oil crops of the world. McGraw-Hill, New York.

Argos P., K. Pedersen, M.D. Marks, and B.A. Larkins. 1982. A structural model for maize zein proteins. J. Biol. Chem. 257:9984-9990.

Barton K.A., J.F. Thompson, J.T. Madison, R. Rosenthal, N.P. Jarvis, and R.N. Beachy. 1982. The biosynthesis and processing of high molec- 
ular weight precursors of soybean glycinin subunits. J. Biol. Chem. 257:6089-6095.

Chrispeels, M.J. 1985. The role of the golgi apparatus in the transport and post-translational modification of vacuolar (protein body) proteins. Oxford Surv. Plant Mol. Cellular Biol. 2:43-68.

Christianson, D.D., U. Khoo, H.C. Nielsen, and J.S. Wall. 1974. Influence of Opaque-2 and Floury-2 genes on formation of proteins in particulates of corn endosperm. Plant Physiol. 53:851-855.

Derbyshire, E., D.J. Wright, and D. Boulter. 1976. Legumin and vicilin, storage proteins of legume seeds. Phytochemistry 15:3-24.

Dickinson, C.D., L.A. Floener, G.L. Lilley, and N.C. Nielsen. 1987. Selfassembly of proglycinin and hybrid proglycinin synthesized in vitro from cDNA. Proc. Natl. Acad. Sci. USA 84:5525-5529.

Dickinson, C.D., E.H.A. Hussein, and N.C. Nielsen. 1989. Role of posttranslational cleavage in glycinin assembly. Plant Cell 1:459469.

Esen, A. 1986. Separation of alcohol-soluble proteins (zeins) from maize into three fractions by differential solubility. Plant Physiol. 80:623-627.

Fehr, W.R. 1989. Soybean, p. 301-318. In: G. Robbelen, R.K. Downey, and A. Ashri (eds.). Oil crops of the world. McGraw-Hill, New York.

Hagen, G. and I. Rubenstein. 1981. Complex organization of zein genes in maize. Gene 13:239-249.

Higgins, T.J.V. 1984. Synthesis and regulation of major proteins in seeds. Annu. Rev. Plant Physiol. 35:191-221.

Hinchee, M.A.W., D.V. Connor-Ward, C.A. Newell, R.E. McDonnell, S.J. Sato. C.S. Gasser. D.A. Fischoff, D.B. Re, R.T. Fraley. and R.B Horsch. 1988. Production of transgenic soybean plants using Agrobactedium -mediated DNA transfer. Bio/Technology 6:915-922.

Hurkman, W.J., L.D. Smith, J. Richter, and B.A. Larkins. 1981. Subcellular compartmentalization of maize storage proteins in Xenopus oocytes injected with zein messenger RNAs. J. Cell Biol. 89:292-299.

Hymowitz, T. 1987. Increasing yields and food and nutritional quality through breeding: Grain legumes, p. 15-24. In: J. DuPont and E.M. Osman (eds.). Cereals and legumes in the food supply. Iowa State University Press, Ames.

Kirihara, J.A., J.P. Hunsperger, W.C. Mahoney, and J.W. Messing. 1988 Differential expression of a gene for a methionine-rich storage protein in maize. Mol. Gen. Genet. 211:477-484.

Kitamura, K. and K. Shibasaki. 1975. Isolation and some physico-chemical properties of the acidic subunits of the soybean 11S globulin. Agr. Biol. Chem. 39:945-951.

Klein, T.M., M. Fromm, A. Weissinger, D. Tomes, S. Schaaf, M. Sletten, and J.C. Sanford. 1988. Transfer of foreign genes into intact maize cells with high-velocity microprojectiles. Proc. Natl. Acad. Sci. USA 85:43054309.

Kramer, B., W. Kramer, and H-J. Fritz. 1984. Different base/base mismatches are corrected with different efficiencies by the methyl-directed DNA mismatch-repair system of E. coli. Cell 38:879-887.

Larkins, B.A. and W.J. Hurkman. 1978. Synthesis and deposition of zein in protein bodies of maize endosperm. Plant Physiol. 62:256-263.

Larkins, B.A., C.R. Lending, J.C. Wallace, G. Galili, E.E. Kawata, K.B. Geetha, A.L. Kriz, D.N. Martin, and C.E. Bracker. 1989. Zein gene expression during maize embryo development, p. 109-120. In: R.B. Goldberg (ed.). The molecular basis of plant development. UCLA Symp. Mol. Cellular Biol. Alan R. Liss, New York.

Lending, C.R., A.L. Kriz, B.A. Larkins, and C.E. Bracker. 1988. Structure of maize protein bodies and immunocutochemical localization of zeins. Protoplasma 143:51-62.

Marks, M.D. and B.A. Larkins. 1982. Analysis of sequence microheterogeneity among zein messenger RNAs. J. Biol. Chem. 260:9976-9983.

Marks. M.D.. J.S. Lindell, and B.A. Larkins. 1985. Nucleotide sequence analysis of zein mRNAs from maize endosperm. J. Biol. Chem. 260:1645116459.

Melton, D.A., P.A. Kreig, M.R. Rebagliati, T. Maniatis, K. Zinn, and M.R. Green. 1984. Efficient in vitro synthesis of biologically active RNA and RNA hybridization probes from piasmids containing a bacteriophage SP6 promoter. Nucleic Acids Res. 12:7035-7056.

Mertz, E.T. 1986. Genetic and biochemical control of grain protein synthesis in normal and high-lysine cereals. World Rev. Nutr. Dietetics 48:222262 .

Mosse, J. and J. Baudet. 1983. Crude protein and amino acid composition of seeds: Variability and correlations. Qualitas Plant. Plant Foods Human Nutr. 32:225-245.
Nelson, O.E. 1969. Genetic modification of protein quality in plants. Adv. Agron. 21:171-194

Nelson, O.E. 1979. Genetic control of polysaccharide and storage protein synthesis in the endosperms of barley, maize, and sorghum. Adv. Cereal Sci. Technol. 3:41-71.

Nielsen, N.C. 1984. The chemistry of legume storage proteins, Philosophical Trans. Royal Soc. London Ser. B. 304:287-296.

Nielsen, N.C. $1985 \mathrm{a}$. The structure and complexity of the $11 \mathrm{~S}$ polypeptides in soybeans. J. Amer. Oil Chem. Soc. 62:1680-1686.

Nielsen, N.C. 1985b. Structure of soy proteins, p. 27-64. In: A.M. Altschul and H.L. Wilcke (eds.). New protein foods. vol. 5. Academic, Orlando, Fla.

Nielsen, N.C., C.D. Dickinson, T.J. Cho, V.H. Thanh, B. J. Scallon, R.L. Fischer, T.L. Sims, G.N. Drews, and R.B. Goldberg. 1989. Characterization of the glycinin gene family in soybean. Plant Cell 1:313-328.

Ortega, E.I. and L.S. Bates. 1983. Biochemical and agronomic studies of two modified hard-endosperm opaque-2 (Zea mays L.) populations. Cereal Chem. 60:107-111.

Osborne, T.B. 1924. The vegetable proteins. Longman, Greens, London.

Pedersen, K., P. Argos, S.V.L. Naravana, and B.A. Larkins. 1986. Sequence analysis and characterization of a maize gene encoding a highsulfur zein protein of $M r$ 15,000. J. Biol. Chem. 261:6279-6284.

Prat, S., J. Cortades, and J. Palau. 1985. Nucleic acid (cDNA) and amino acid sequences of the maize endosperm protein glutelin-2. Nucleic Acids Res. 13:1493-1504.

Rhodes, C.A., D.A. Pierce, I.J. Mettler, D. Mascarenhas, and J.J. Detmer. 1988. Genetically transformed maize plants from protoplasts. Science 240:204-207

Righetti, P.G., E. Gianazza, A. Viotti, and C. Soave. 1977. Heterogeneity of storage proteins in maize. Planta 136:115-123.

Rubenstein, I. and D.E. Geraghty. 1986. The genetic organization of zein. Adv. Cereal Sci. Technol. 8:297-315.

Shannon, J.C. and D.L. Garwood. 1984. Genetics and physiology of starch development, p. 25-86. In: R.L. Whistler, J.N. BeMiller, and E.F. Paschall (eds.). Starch: Chemistry and technology. 2nd ed. Academic, New York

Shotwell, M.A. and B.A. Larkins. 1989. The biochemistry and molecular biology of seed storage proteins, p. 297-345. In: A. Marcus (ed.). The biochemistry of plants: A comprehensive treatise. vol. 15. Academic, Orlando, Fla.

Smith, A.K. and S.J. Circle. 1972. Chemical composition of the seed, p. 61-92. In: A.K. Smith and S.J. Circle (eds.). Soybeans: Chemistry and technology. vol. 1. AVI Westport, Conn.

Soave, C. and F. Salamini. 1984. Organization and regulation of zein genes in maize endosperm. Philosophical Trans. Royal Soc. London Ser. B. 304:341-347

Spena, A., A, Viotti, and V. Pirrotta. 1982. A homologous repetitive block structure underlies the heterogeneity of heavy and light chain zein genes. EMBO J. 1:1589-1594

Staswick, P.E., M.A. Hermodson, and N.C. Nielsen. 1984. Identification of the cystines which link the acidic and basic components of the glycinin subunits. J. Biol. Chem. 259:13,431-13,435

Turner N.E., J.D. Richter, and N.C. Nielsen. 1982. Structural characterization of the glycinin precursors. J. Biol. Chem. 257:4016-4018.

Wallace, J.C., G. Galili, E.E. Kawata, R.E. Cuellar, M.A. Shotwell, and B.A. Larkins. 1988a. Aggregation of lysine-containing zeins into protein bodies in Xenopus oocytes. Science 240:662-664.

Wallace, J.C., G. Galili, E.E. Kawata, C.R. Lending, A.L. Kriz, C.E Bracker, and B.A. Larkins. 1988b. Location and interaction of the different types of zeins in protein bodies. Biochem. Physiol. Pflanzen. 183:107-115.

Weber, E.J. 1987. Lipids of the kernel, p. 311-359. In: S.A. Watson and P.E. Ramstad (eds.). Corn: Chemistry and technology. Amer. Assn. Cereal Chem., St. Paul.

Wilson, C.M. 1984. Isoelectric focusing of zein in agarose. Cereal Chem. 61:198-200.

Wilson, C.M. 1987. Proteins of the kernel, p. 273-310. In: S.A. Watson and P.E. Ramstad (eds.). Corn: Chemistry and technology. Amer. Assn. Cereal Chem., St. Paul.

Wilson, D.R. and B.A. Larkins. 1984. Zein gene organization in maize and related grasses. J. Mol. Evolution 20:330-340. 